\title{
STUDY ON COMBUSTION PROCESS IN LARGE BORE TWO-STROKE GAS ENGINES GMVH-12
}

\author{
R. Ślefarski*, M. Gołębiewski**, J. Wawrzyniak***
}

\begin{abstract}
The paper presents the results of experimental study of two-stroke, large gas engine GMVH-12 before and after modernization process. During fuel suppling control system retrofitting as well as type of intake valves were changed. Investigations have been performed for different operation parameters like ignition delay time, boost pressure and rotational speed. In the analysis $N O_{X}$ emission, specific fuel consumption index and coefficient of peak variation were included.
\end{abstract}

Keywords: gas engines, NOx emission, two-stroke engine, combustion stability, retrofit

\section{Introduction}

All new combustion technologies in the EU as well as in other developed countries have to fulfil new emission limits described in EU directives and also other legislations standard like: Directive 2015/2193 (2015), Industrial Emission Directive IED (2010) or Best Available Techniques conclusions BAT (2017). To achieve these requirements it is necessary to use new low-emission combustion technologies or adapt to new limits existing energy machines. One of the group of machines which have to fulfil new more restricted emission limits are reciprocating engines fuelled by gaseous fuels. Such devices are used in energetic sector for electricity production or are used for power generation in industrial processes like gas air compression, natural gas storage and transportation.

There are two types of engines used in gas industry: modern four-stroke low emission units and older twostroke engines. In the case of the latter ones the most common is GMVH family. Depending on the type of configuration, operating conditions and required power it can consist of 8,12 and 16 cylinders. It is estimated that in the transition system of natural gas in Easter Europe (Poland, Lithuania) as well in Russia there is about 100 units of GMVH engines (Rojewski et al., 2013) and next 1500 $\div 2500$ in the rest of World. These engines are characterized by low efficiency and high emission of toxic compounds especially: nitric oxides $\left(\mathrm{NO}_{\mathrm{x}}\right.$ ); carbon monoxide $(\mathrm{CO})$ or unburned hydrocarbons (THC). The amount of toxic compound which are emitted to the atmosphere is strongly connected with the parameters of combustion process. In case of gas engines the most important are: air equivalence ratio $(\lambda)$, maximum temperature $\left(T_{c}\right)$, repeatability of ignition, engine load or boost pressure. The main reason of THC and CO formation is lack of ignition or pure mixing of fuel-air. Nitric oxides in reciprocating engines as well as gas turbines are formed mainly by thermal mechanism (Warnatz et al., 2006). According to this mechanism an amount of nitric oxide depends on $\lambda$ and temperature, and they rises with temperature increase. Promising method of $\mathrm{NO}_{\mathrm{X}}$ reduction is burning of lean mixtures (Urbaniak et al., 2015). It caused decreasing of maximum temperature inside the combustion chamber but it entails the necessity of introduction an high energy ignition systems, e.g., pre-combustion chamber (PCC) (Olsen et al., 2017; Ślefarski et al., 2018). Tozzi et

Rafał Ślefarski, PhD.: Chair of Thermal Engineering, Poznań University of Technology, Street Piotrowo 3, 60-965, Poznań; PL rafal.slefarski@put.poznan.pl

** Michał Gołębiewski, PhD student.: Chair of Thermal Engineering, Poznań University of Technology, Street Piotrowo 3, 60965, Poznań; PL michal.e.golebiewski@doctorate.put.poznan.pl

*** Jacek Wawrzyniak, PhD.:Polisch Oil \& Gas Company, Branch KRIO Odolanów, Street Krotoszyńska 148, 63-430 Odolanów; PL jacek.wawrzyniak@pgnig.pl 
al. (2017) during study on combustion of lean mixture confirmed $34 \%$ reduction of $\mathrm{NO}_{\mathrm{x}}$ with $1 \%$ gain in engine efficiency in case of novel PCC technology with unique vortex flow compared to $30 \%$ reduction of $\mathrm{NO}_{\mathrm{X}}$ in classical PCC approach. Another methods of increasing efficiency of the engine and reduction of harmful compounds from two-stroke gas engine could be: exhaust gas recirculation, swirl injection valves and change of boost pressure.

Study of external gas recirculation (EGR) for a single cylinder spark-ignition Ricardo engine presented by Ibrahim and Bari (2010) shows decrease of NO emissions up to $50 \%$ at both atmospheric and supercharged inlet conditions. Results of EGR analysis presented by Rudkowski et al. (2010) for two stroke gas engine GMVH-8 indicated over $30 \%$ of $\mathrm{NO}_{\mathrm{x}}$ reduction with simultaneous decrease of overall engine efficiency by $3 \%$. In the work Königsson et al. (2013) noticed reduction of hydrocarbon emissions by $20 \%$ and an increase of engine efficiency in case of applying different valve lift profiles for the intake valves. Rising of swirl number from 0.4 to 3.0 improve mixing between $\mathrm{CH}_{4}$ and air and create internal recirculation zone (IRZ) which allows decrease maximum combustion temperature and $\mathrm{NO}_{\mathrm{x}}$ formation (Szewczyk et al., 2015). Intake air pressure boosting is an effective method which allows increase amount of air to be supplied to the combustion chamber through the increasing the density of the intake charge (Heywood, 1988). Thanks to that thereby enhancing the maximum power output from engine and decrease amount of nitric oxides emission (Nagalingam et al., 1983). Reduction of toxic compound is also possible by secondary methods like selective catalytic reduction or reburning process (Ślefarski et al., 2018).

The main objective of investigations presented in this article was to analyse and quantify the benefits of two stage retrofitting process of two-stroke, large bore reciprocating gas engine by implementing of new fuel and air delivery system (Case II) and modification of operation parameters such as: ignition delay time and boost pressure (Case III).

\section{Test object}

The research was conducted on engine of motocompressor GMVH-12 type from Cooper-Bessemer company (Figure 1). It is two-stroke gas engine with 12 cylinders in $\mathrm{V}$ configuration and direct injection of gas fuel. Pistons of compressor are connected with engine pistons by common connecting rod. Nominal power of the engine is $1790 \mathrm{~kW}$ with $330 \mathrm{rpm}$. Boost air pressure is equal $38 \mathrm{kPa}$ and it is generated by turbo charger ET-18.

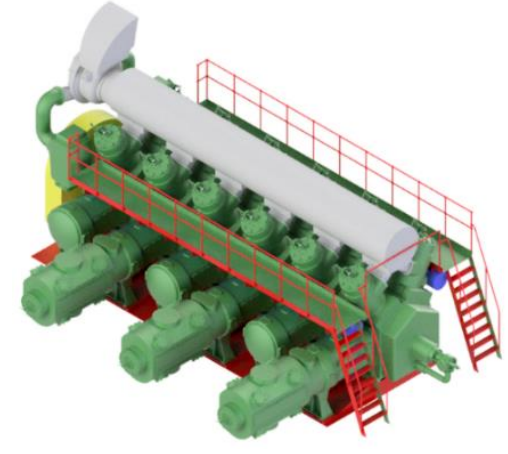

Fig. 1: Cooper-Bessemer GMVH12 engine.

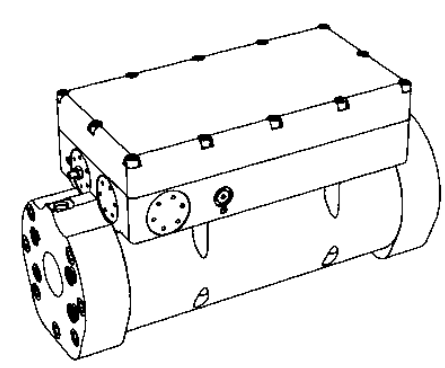

Fig. 2: Control valve Altronic GOV 10/50.

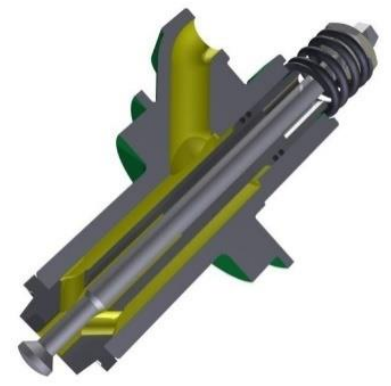

Fig.3: Swirl injector valve.

Investigation of GMVH-12 engine was divided on three stages. First stage (Case I) was performed to determine operating parameter of the standard configuration of this engine. Engine has undergone a general overhaul and it had works over 1000 hours before measurements. It was necessary to make fit every working parts of the engine. Thanks that engine could work with design parameters.

In second stage (Case II) of investigation engine was modernized. Self-contained speed governor and fuel control valve GOV 10/50 from Altronic company was installed (Fig. 3). Thanks that valve it was possible to set engine rotation speed with accuracy equal to $1 \mathrm{rpm}$. Additionally, new type of injection gas valve was installed (Fig. 2) which have new design of nozzles with different output angle. This solution provide swirl flow of gas into the cylinder and better mixing of fuel-air mixture.

The aim of third step of work (Case III) was to increase the boost pressure of the engine. For this purpose new bypass system for ET-18 turbocharger was designed. It allows to direct all of exhaust gases in to the turbine. This modification allows to get boost pressure around $47 \mathrm{kPa}$ for full load of engine. Higher air pressure causes danger of knocking combustion. The ignition system and delayed ignition time (ignition angle) by 5 degrees BTDC was adjusted to protect engine from this phenomena. 


\section{Test method}

The main investigation goal was to analyze the impact of GMVH-12 engine modification on its operation parameters and emission of harmful compounds especially nitric oxides $\left(\mathrm{NO}_{\mathrm{X}}\right)$. For this purpose measurements parameters like: indicated pressure, fuel gas consumption and exhaust gases composition were taken. Regulation of engine load was performed by regulation of engine crankshaft rotation speed in the range 270-330 rpm. This is the only way to control this engine type in industrial condition.

Measurement of the pressure was made by pressure transmitter connected with data analysis system Kistler 2507. This system allows to measure change of pressure inside cylinder every 0.5 degree of crankshaft rotation. In addition, it was possible to get information about maximum and minimum peak of pressure $\left(p_{\text {peak }}\right)$ from 10 work cycles of one cylinder. Engine power was calculated as sum of power of all cylinders $\left(\mathrm{N}_{\mathrm{i}}\right)$. Exhaust gas composition was measured by set of gas analysers Emerson Rosemount $\mathrm{O}_{2}, \mathrm{NO}_{\mathrm{X}}, \mathrm{CO}$, $\mathrm{CO}_{2}$ ) with accuracy of $1 \%$ of the full scale. For experimental analysis results the specific fuel consumption $\mathrm{g}_{\mathrm{i}}$ and coefficient of variation of peak pressure in cylinders $\mathrm{COP}_{\mathrm{p}}$ were calculated according formula (1) and (2). In the formula (2) $x_{i}$ is maximum peak of pressure, $\bar{x}$ is average peak of pressure, while $n$ is the number of cylinders.

$$
g_{i}=\frac{Q_{f}}{N_{i}}\left[\frac{\mathrm{Nm}^{3}}{k W h}\right]
$$

$$
\operatorname{CoV}=\frac{\sqrt{\sum_{\mathrm{i}=1}^{\mathrm{N}}\left(\mathrm{x}_{\mathrm{i}}-\overline{\mathrm{x}}\right)^{2} / \mathrm{n}}}{\overline{\mathrm{x}}} \cdot 100 \%
$$

\section{Results and discussion}

Results of investigation are presented in the Figure 4 and 5. For base configuration of engine (Case I) $\mathrm{NO}_{\mathrm{X}}$ emission was almost constant for all investigated rotation speeds with average value of $3247 \mathrm{ppm}$. For this configuration the specific fuel consumption was at level of $0.274 \mathrm{Nm}^{3} / \mathrm{kWh}$.
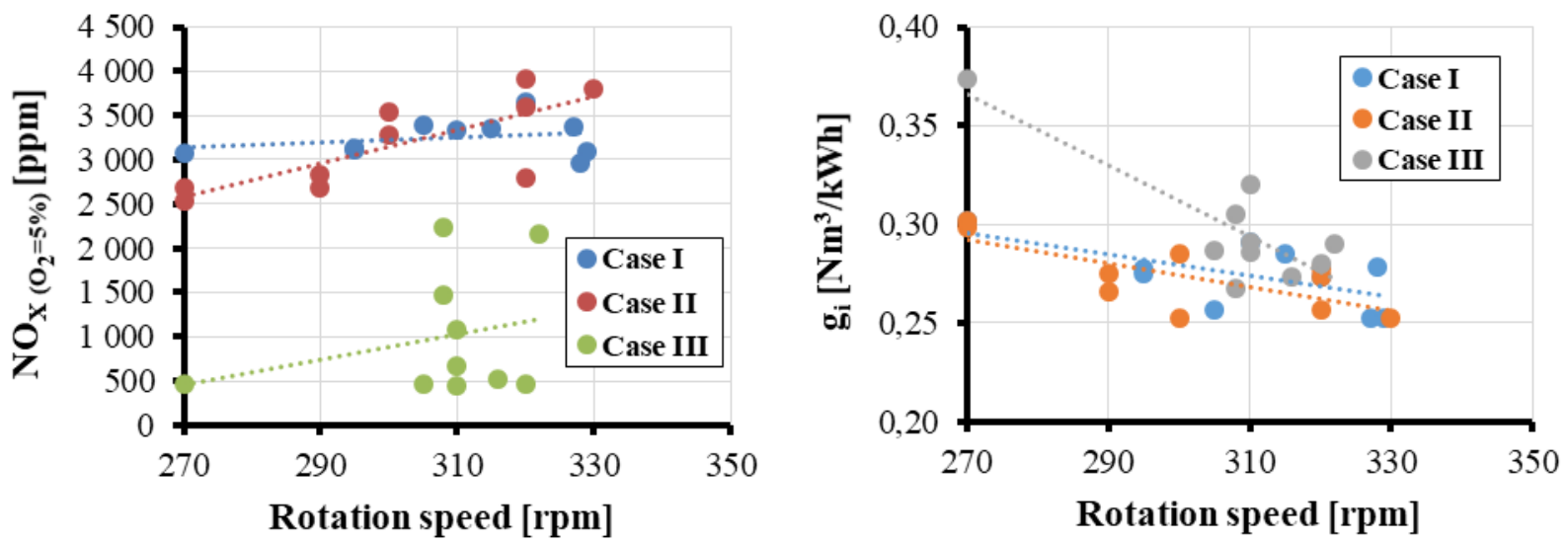

Fig. 4: Emission of $\mathrm{NO}_{X}$ (left) and specific fuel consumption (right) for GMVH-12 engine.
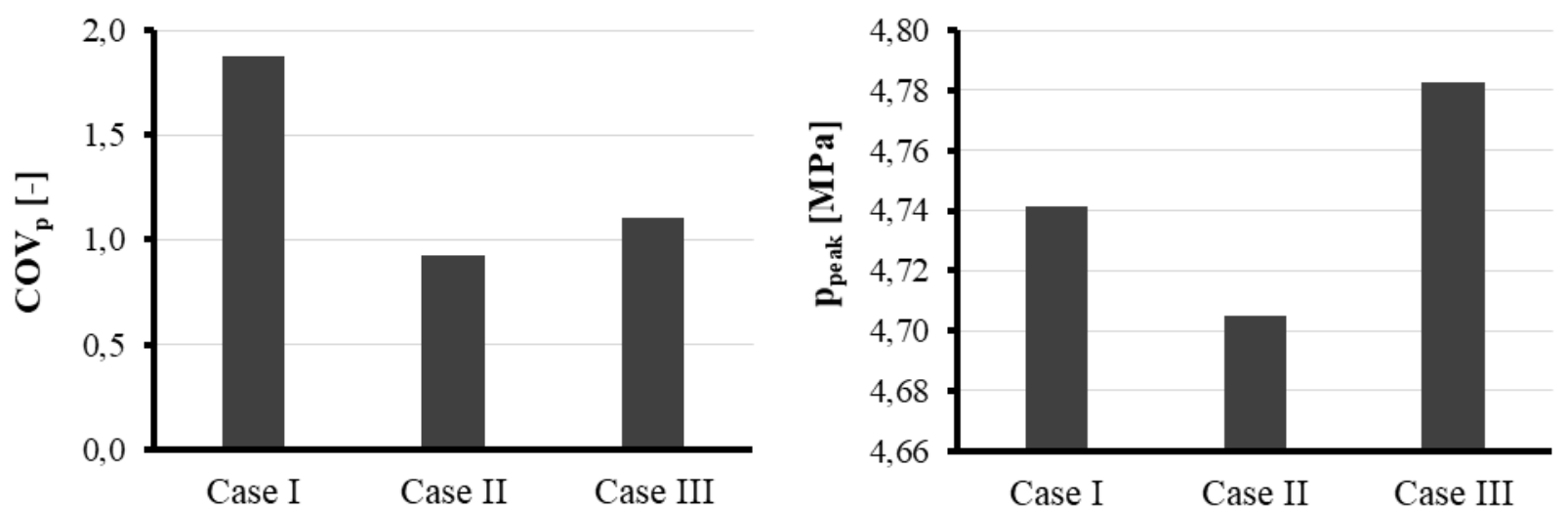

Fig. 5: $\mathrm{COV}_{p}$ coefficient (left) and maximum peak of pressure (right) for GMVH-12 engine.

Installation of GOV valve and new gas injection valves decrease average emission of $\mathrm{NO}_{\mathrm{x}}$ by $2.5 \%$. The highest nitric oxides reduction (17\%) was observe for low load of engine (270 rpm). The opposite 
phenomena was observed for the highest engine load where the $\mathrm{NO}_{\mathrm{X}}$ increases by $6.5 \%$.After modernization $\mathrm{COV}_{\mathrm{p}}$ coefficient decrease by over 50\% which results in lower amount of THC (data not presented in the paper) and decrease of specific fuel consumption value by around $1 \%$. This improvement is caused by better fuel and air mixing inside cylinder which ensure combustion stability and more spatial character of combustion process.

In third step of investigations (Case III) the boost pressure was change. An increase of charging pressure caused positive impact on nitric oxides emission. In comparison with Case II almost $69 \%$ reduction was observed. This is result of equivalent ratio decrease by supplying of additional amount of air which provide to the more lean combustion process. Unfortunately such solution provide high difference of emission between the same measuring points reaching $80 \%$. The second negative aspect is an increase e of $\mathrm{COV}_{\mathrm{p}}$ value coefficient by $19 \%$ which leads to increase of fuel consumption value by around $8.6 \%$. Such combustion instability is the result of lack of ignition caused by shifting the ignition angle to $-2^{\circ}$ BTDC.

\section{Conclusion}

Investigations presented in this paper show possibility of two-stroke gas engine retrofitting by modernization of fuel intake system as well as improving of turbocharger work. Modernization of fuel system provided an increase of combustion stability by $50 \%$ and decrease of fuel consumption by $1 \%$. For low rotational speed $\mathrm{NO}_{\mathrm{x}}$ reduction up to $17 \%$ was noticed, while for full load of engine the nitric oxides emission rises by $6.5 \%$.

Increasing of charging pressure over $45 \mathrm{kPa}$ (Case III) ensures significant reduction of nitric oxides up to $69 \%$ in whole range of investigated engine load. However, to avoid knocking combustion process, the ignition time delay was changed to $-2^{\circ}$ BTDC which resulted in negative phenomena such as increase of combustion instability by $19 \%$ and fuel consumption by $8.6 \%$.

\section{References}

Commission Implementing Decision (EU) 2017/1442 of 31 July 2017 establishing best available techniques (BAT) conclusions, under Directive 2010/75/EU of the European Parliament and of the Council, for large combustion plants. (2017). Official Journal of the European Union EN.

Directive (EU) 2015/ 2193 Of The European Parliament And Of The Council - of 25 November 2015 - on the limitation of emissions of certain pollutants into the air from medium combustion plants. (2014). Official Journal of the European Union EN (Vol. 451).

Directive 2010/75/EU (IED) of the European Parliament and of the Council, on industrial emissions (integrated pollution prevention and control). (2010).

Heywood, J. B. (1988). Internal combustion engine fundamentals. new York: McGraw-Hill.

Ibrahim, A., \& Bari, S. (2010). An experimental investigation on the use of EGR in a supercharged natural gas SI engine. Fuel, 89(7), 1721-1730.

Königsson, F., Dembinski, H., \& Angstrom, H.-E. (2013). The Influence of In-Cylinder Flows on Emissions and Heat Transfer from Methane-Diesel Dual Fuel Combustion. SAE International Journal of Engines, 6(4), 2013-012509.

Nagalingam, B., Dübel, M., \& Schmillen, K. (1983). Performance of the supercharged spark ignition hydrogen engine. In 1983 SAE International Fall Fuels and Lubricants Meeting and Exhibition. SAE International.

Olsen, D. B., Adair, J. L., \& Willson, B. D. (2017). Precombustion Chamber Design And Performance Studies, 1-14.

Rojewski, J., Ślefarski, R., \& Wawrzyniak, J. (2013). Analysis of combustion process in industrial gas engines powered with high methane and nitrified low-calorific gases. Combustion Engines, 52, 42-50.

Rudkowski, M., Dudek, S., \& Wołoszyn, R. (2010). Test results of an external exhaust gas recirculation system of a Cooper Bessemer GMVH-8 engine-compressor, 2010(2).

Szewczyk, D., Jankowski, R., Ślefarski, R., \& Chmielewski, J. (2015). Experimental study of the combustion process of gaseous fuels containing nitrogen compounds with the use of new, low-emission Zonal Volumetric Combustion technology. Energy, 92.

Ślefarski, R., Gołębiewski, M., Czyżewski, P., Grzymisławski, P., \& Wawrzyniak, J. (2018). Analysis of Combustion Process in Industrial Gas Engine with Prechamber-Based Ignition System. Energies, 11(2), 336.

Ślefarski, R., Jójka, J., Czyżewski, P., \& Grzymisławski, P. (2018). Experimental investigation on syngas reburning process in a gaseous fuel firing semi-idustrial combustion chamber. Fuel, 217.

Tozzi, L., Sotiropoulou, E., \& Zhu, S. (2017). Improving the efficiency/emissions trade-off with a novel lean-burn precombustion chamber (pp. 165-176). Dessau: 10. Dessauer Gasmotoren-Konferenz.

Urbaniak, R., Bartoszewicz, J., \& Kłosowiak, R. (2015). Main Causes of NOx Emissions by Low-Power boilers. Polish Journal of Environmental, 24(5), 2223-2230.

Warnatz, J., Dibble, R., \& Maas, U. (2006). Combustion, physical and chemical fundamentals modeling and simulation, experiments, pollutant formation. 